УДК 94 (517.3+571.54)

ГОМБОЖАПОВ Александр Дмитриевич - кандидат исторических наук, ведущий научный сотрудник отдела истории и культуры Центральной Азии Института монголоведения, буддологии и тибетологии СО РАН (670042, Россия, Республика Бурятия, г. Улан-Удэ, ул. Сахьяновой, 6; agoтbоzh@ gmail.com)

\title{
ЗАМЕТКИ О КОЧЕВНИЧЕСТВЕ СОВРЕМЕННОЙ МОНГОЛИИ: АНТРОПОЛОГИЯ РЕСУРСНОГО КОНФЛИКТА
}

Аннотация. В статье предпринята попытка раскрыть основные противоречия в развитии современного кочевого общества Монголии. Автор отмечает, что традиционный кочевой уклад сталкивается с рядом вызовов. Динамичный рост добывающего сектора экономики увеличил площадь изымаемых пастбищных угодий для разработки новых месторождений полезных ископаемых. Номады вынуждены также конкурировать за ресурсы с производителями сельскохозяйственных культур, ежегодно расширяющих посевные площади. Увеличивающееся поголовье скота в условиях дефицита пастбищного фонда способствует нарастанию экологических угроз и социальной напряженности между кочевниками, вынужденными вступать в борьбу за естественные ресурсы.

Ключевые слова: Монголия, кочевники, кочевое хозяйство, ресурсы, конфликт

$\mathrm{O}$ дной из крупных проблем развивающихся стран является многоукладность экономики. Наряду с формирующимися современными рыночными отношениями немалую долю в этих странах занимают натурально-хозяйственные отношения. Монголия, где долгое время существовала плановая экономика, после реформ 1990-х гг. прошлого столетия вступила в полосу длительного экономического и социального кризиса. Попытка резкого скачкообразного перехода к рыночной экономике отбросила развитие страны на десятки лет назад. Были нарушены и прерваны хозяйственные связи, произошел всплеск безработицы, начался неконтролируемый рост инфляции. Все это способствовало тому, что значительная часть населения была вынуждена в поисках прожиточных доходов обратиться к малым натуральным формам хозяйствования. В условиях Монголии это, прежде всего, возрождение традиционных форм скотоводческого хозяйства и связанного с ним кочевого образа жизни [Грайворонский 1997]. Для подавляющей части сельских жителей, которые составляют одну треть общего числа населения, пастбищное животноводство является основным источником экономического и социального благополучия.

На сегодняшний день в Монголии сложилась смешанная многоукладная экономика. Противоречия, сопровождающие явление многоукладности, выражены не только в экономике, но и проявляются в сфере социально-правовых отношений. Экономический подъем нулевых годов, основой которого стал экспорт сырьевых ресурсов, привел к активизации деятельности во многих отраслях промышленности и сельского хозяйства. За счет зарубежных инвестиций стали разрабатываться новые крупные месторождения каменного и бурого угля, меди, золота, серебра и других полезных ископаемых. Развитие внутреннего спроса, реализация национальных программ продовольственной безопасности страны, в т.ч. за счет поддержки малых фермерских хозяйств, привели к росту темпов производства в сельском хозяйстве. В условиях быстрого роста рыночной экономики пастбищное землепользование столкнулось с серьезной конкуренцией со стороны предприятий горнодобывающей промышленности [Suzuki 2013] и производителей сельскохозяйственных культур, которые, в отличие от 
традиционных общинных представлений кочевников о праве собственности на землю, основываются на позитивном праве, и в этом случае их права гарантированы и защищены государством.

В Монголии сосредоточены крупные месторождения полезных ископаемых. По их доказанному объему страна входит в первую десятку государств, обладающих самыми большими запасами минеральных ресурсов. Динамичное развитие горнодобывающей отрасли, пик которого пришелся на 2011 г., было обеспечено высокими ценами на сырье на мировом рынке. Это привело к увеличению числа вводимых в разработку новых месторождений. Несмотря на последующий спад, причиной которого стало падение цен в 2014-2016 гг., добывающая промышленность остается основным драйвером экономического развития. В конце 2016 г. в Монголии было выдано в общей сложности 3580 лицензий на разведку и добычу полезных ископаемых (из них 2022 приходятся на разведку и 1558 - на добычу) ${ }^{1}$. На горнодобывающую промышленность приходится около $1 / 4$ ВВП и более $80 \%$ экспорта.

На подавляющем большинстве месторождений добыча в силу относительной дешевизны ведется открытым способом. Существует также нелегальная добыча золота мелкими артелями самым примитивным кустарным способом, зачастую опасными для здоровья методами (например, ртутное амальгамирование) [Бадараев 2014; Михалев 2012].

Интересы крупных и мелких добывающих компаний по освоению новых месторождений входят в явное противоречие с хозяйственной деятельностью кочевого населения. В ходе добычи полезных ископаемых наносится серьезный экологический урон (загрязняются почвы, воздух, реки и грунтовые воды, нарушается водный режим). Из земельного оборота изымаются обширные площади, в т.ч. пастбищные земли. Все это не может не вызвать недовольство со стороны местных скотоводов.

Положение дел в сфере земельного законодательства и правоприменения не способствует разрешению конфликта хозяйственных интересов. Пастбищные угодья по закону о земле 2002 г. рассматриваются как общее достояние граждан Монголии. А в отсутствие надлежащих прав на землю пастбищ для скотоводства они часто рассматриваются как свободные земли, доступные для продажи или сдачи в аренду частным инвесторам. Кочевники в правовом отношении остаются беззащитными перед угрозой изъятия земель под разработку месторождений полезных ископаемых добывающими компаниями, поскольку не могут официально оформить свои пастбищные участки в собственность или в долгосрочную аренду [Barcus 2018].

Хотя 16 июля 2009 г. под давлением протестных настроений парламент страны принял закон о запрете на геологическую разведку и добычу полезных ископаемых в верховьях рек, водоохранных зонах и лесах, практического применения он не находит. До сих пор окончательно не проведены межевые и инвентаризационные работы, определяющие конкретные границы указанных в законе территорий.

Кочевым домохозяйствам приходится также противостоять производителям сельскохозяйственных культур и конкурировать с ними. После «шоковой терапии» 1990-х гг. наступил длительный упадок в растениеводческой отрасли. Из сельскохозяйственного оборота была выведена значительная доля посевных площадей. Если в 1989 г. было засеяно разными культурами около 838 тыс. га,

1 The Annual report 2016. Geology, Mining, Petroleum, Heavy industry. Mineral Resources and Petroleum Authority of Mongolia. 147 p. 
то в 2006 г. - всего лишь 162 тыс. га 1 . За этот период эти земли стали использоваться как пастбища. Бывшие члены развалившихся колхозов и госхозов стали разводить домашний скот, на бесхозных землях стали поселяться кочевники, прибывшие из отдаленных регионов страны. Заметим, что миграции кочевников стали заметным социально-экономическим явлением в современной Монголии. Их общий вектор направлен к городам, которые расположены в Центральной Монголии и как крупные рынки сбыта животноводческой продукции притягивают к себе номадов.

В 2008 г. постановлением правительства Монголии была утверждена национальная программа «Атрын III аян». Ее целью стали восстановление посевных площадей, плодородия почв, внедрение инноваций, сокращение импорта сельхозпродукции и содействие устойчивому развитию ориентированного на экспорт фермерского хозяйства. По данным статистики за 2018 г., общая посевная площадь составила 507,9 тыс. га. Основные высаживаемые культуры - пшеница, картофель, масличные, облепиха. Из них Монголия за счет собственного производства полностью покрывает потребности в картофеле (168,9 тыс. т) и пшенице $\left(425,8\right.$ тыс. т) ${ }^{2}$.

В центральных районах страны наблюдается наиболее острый конфликт интересов. Так, по заявлению местных фермеров Селенгинского аймака, доля потерь, относимых на счет потрав, достигает $30 \% 3$. В свою очередь, для кочевников распашка полей резко сужает возможности выпаса скота, делает труднодоступными реки и озера, вынуждает подолгу утилизировать пастбища с бедной растительностью, что неблагоприятно отражается на кочевом хозяйстве.

В 2018 г. монгольское правительство, учитывая слабую упорядоченность и социальную напряженность в отношениях между животноводами и растениеводами, вынесло постановление о сельскохозяйственном районировании. К земледельческому поясу были отнесены 60 сомонов, входящих в 7 аймаков Монголии (Селенгинский, Булган, Центральный, Увэрхангай, Хэнтэй, Архангай и Дархан $)^{4}$. Для кочевников-животноводов предложена программа с государственной поддержкой по переходу от экстенсивных форм скотоводческого хозяйства к интенсивным. В ее рамках предполагаются выделение субсидий и кредитов для строительства надворных построек со стойловым содержанием скота, бурение скважин для организации водопоя домашних животных, закупка КРС молочного направления и т.д.

Кроме конфликта интересов между субъектами с разной хозяйственной деятельностью, т.е. внешней конкуренции за ресурсы, нарастает внутренняя борьба за пастбища среди самих кочевников. Пастбищный фонд Монголии составляет 112,1 млн га, из которых 1,7 млн приходятся на сенокосные угодья. В силу сезонного характера утилизации пастбищные угодья подразделяются на используемые в зимне-весенний (52,9 млн га) и в летне-осенний (60,3 млн. га) периоды. За последние десятилетия сложилась устойчивая тенденция сокращения пастбищных земель: по сравнению с 1964 г. их площадь уменьшились на

1 Нийт тариалсан талбай, улс, бүс, аймаг, нийслэл, жилээр. - Статистикийн мэдээлийн нэгдсэн сан. Доступ: http://www.1212.mn/tables.aspx?tbl_id=DT_NSO_1002_003V1\&SOUM_select_ all $=0 \&$ SOUMSingleSelect $=$ _0\&YearY_select_all $=1 \&$ YearYSingleSelect $=\&$ viewtype $=$ linechart 07.06.2019).

2 Монгол Улс улаанбуудай болон төмсний дотоодын хэрэгцээг 100 хувь хангах боломж бүрдлээ. - Хүнс, хөдөө аж ахуй, хөнгөн уйлдвэрийн яам. Доступ: http://mofa.gov.mn/exp/article/entry/1428 (проверено 07.06.2019).

3 Газар тариалангийн бүс нутгийг тогтоолоо. - Өдрийн Тойм. 17.05.2018 г. Доступ: http://udriintoim. $\mathrm{mn} /$ (проверено 07.06.2019).

47 аймгийн 60 сумын 113 багийг тариалангийн бүс нутгаар тогтоолоо. - Хүнс, хөдөө аж ахуй, хөнгөн үйлдвэрийн яам. Доступ: http://mofa.gov.mn/exp/article/entry/1115 (проверено 07.06.2019). 
9 млн га1. Ученые уже давно бьют тревогу из-за увеличивающейся деградации пастбищ вследствие многократного превышения предельно допустимых норм по их нагрузке [Грайворонский 2018]. Во многих областях растительность на естественных пастбищах не успевает восстанавливаться. Это напрямую связано с рекордным ростом общего поголовья скота в стране, которое, по данным за 2018 г., насчитывает уже около 66,4 млн голов ${ }^{2}$.

Не вдаваясь в подробности причин столь динамичного развития животноводческой отрасли, которые разобраны в статье известного монголоведа В.В. Грайворонского [Грайворонский 2018], хотелось бы отметить, что для такого поголовья скота естественных пастбищных ресурсов Монголии явно недостаточно. Его круглогодичное содержание не может обойтись уже без ущерба для пастбищной экосистемы [The Mongolian ecosystem... 2012]. Нехватка пастбищных земель на фоне растущего поголовья приводит к меньшей подвижности кочевых домохозяйств. Это означает, что вместо сезонного выпаса, подразумевающего деление пастбищных угодий на зимние, весенние, летние и осенние, кочевники круглогодично используют одни и те же пастбища.

Увеличение плотности кочевых домохозяйств ведет к острой конкуренции между ними. При отсутствии четких правовых механизмов защиты прав кочевников на пользование пастбищными угодьями происходит формирование локальных групп, члены которых объединяются для защиты собственных интересов. Они носят неформальный характер, и хотя, как показывают наблюдения автора в центральных и южных сомонах Хэнтэйского аймака Монголии, они образованы по территориальному принципу, однако же состоят из скотоводов, связанных между собой отношениями родства и свойства. Они не допускают кочевок сторонних по «своим» пастбищам. В случае попытки разбить временное стойбище члены этой локальной общины могут использовать силовые методы для того, чтобы прогнать прибывших кочевников. Все это не может не напоминать архаичные коллективные формы социальной организации, свойственные традиционному обществу. На зимних и весенних стоянках, на которые выдаются документы о праве собственности, возводятся дома и долговременные постройки, что свидетельствует о первичных процессах оседания кочевников. Де-факто речь идет о закреплении земель общего пользования в собственности определенной группы людей - местной кочевой общины. Хотя и нет визуально определяемых границ, все же они присутствуют, и каждый местный скотовод знает и соблюдает эти границы. Это, конечно, мало соотносится с представлениями о вольном перемещении кочевников, о традиционном их праве размещаться в любом месте, где они посчитают для себя нужным. Следует отметить, что чем выше плотность кочевых домохозяйств, а она, как правило, возрастает вблизи крупных городов, тем явственнее обозначены границы кочевых общин. Примером могут служить окрестные территории столицы Монголии г. УланБатора ${ }^{3}$.

Вышесказанное ни в коей мере не говорит о том, что государство и местные власти отстранены и никак не участвуют в регуляции взаимоотношений в сфере пастбищного землепользования и земельного оборота. Напротив, государство принимает самое деятельное участие, определяя базовые правовые

\footnotetext{
${ }^{1}$ Бэлчээрийн хүрэлцээ, хангамж. - Хүнс, хөдөө аж ахуй, хөнгөн үйлдвэрийн яам. Доступ: http://mofa. gov.mn/exp/blog/7/6 (проверено 07.06.2019)

2 Мал аж ахуй. Нийт малын тоо 2018 оны байдлаар. - Статистикийн мэдээлийн нэгдсэн сан. Доступ: https://www.1212.mn/stat.aspx?LIST_ID=976_L10_1 (проверено 07.06.2019).

3 World Bank. 2015. Mongolia - Land administration and management in Ulaanbaatar (Mongolian). Wash. DC: World Bank Group. URL: http://documents.worldbank.org/curated/en/300521468120280670/ Mongolia-Land-administration-and-management-in-Ulaanbaater (accessed 07.06.2019).
} 
принципы этих отношений. Однако отсутствие оснований и пробелы в законодательстве существенно ограничивают возможности правового регулирования отношений, возникающих по поводу владения, пользования и распоряжения пастбищными угодьями. Согласно ст. 16 закона о земле местные власти могут оформлять и выдавать правоустанавливающие документы на сельскохозяйственные земли только двух категорий. Это выделение земель «для особых нужд», под которыми подразумеваются так называемые страховые, резервные пастбища (пастбища для отора), и «общественные сенокосные угодья». Они предназначены для использования в периоды бескормицы, часто случающиеся вследствие стихийных бедствий. Весь остальной пастбищный фонд находится в общественной собственности и общем пользовании.

Коренным условием экстенсивного животноводства является насущная потребность в постоянной смене пастбищ, удовлетворение которой возможно только при отсутствии частной формы землевладения. Традиционному кочевому хозяйству глубоко чуждо огораживание и чересполосица. С другой стороны, без четкого юридического закрепления границ пастбищных угодий кочевники остаются беззащитными перед любым посягательством на их земли. В этом состоит основное противоречие развития кочевого хозяйства Монголии. Необходимо отметить, что сложившаяся ситуация не является чем-то уникальным. Схожие процессы можно наблюдать и в других развивающихся странах, расположенных в аридных регионах мира [Babiker 2001; Zhang, Borjigin, Zhang 2007; Hannam 2017].

Таким образом, можно заключить, что в настоящее время кочевничество в Монголии находится на этапе серьезных преобразований. Кочевники вынуждены отстаивать свои права и вести борьбу за естественные ресурсы. За последние годы перед государством остро встала проблема землепользования, общественная значимость которой усиливается по мере ускоренного роста добывающей промышленности, развития земледелия и углубления частнособственнических отношений. Решение этой проблемы затрагивает фундаментальные основы традиционного кочевого общества Монголии. Идеи общинности и социальной справедливости, основанные на традиционном мировоззрении, входят в очевидное противоречие с современными рыночными отношениями.

Статья подготовлена в рамках государственного задания (проект ХІІ.191.1.2. «Межкультурное взаимодействие, этнические исоциально-политическиепроцессыв Центральной Азии», номер госрегистрации № АAАA-А17-117021310264-4).

\section{Список литературы}

Бадараев Д.Д. 2014. Современные «ниндзя»: масштабы и последствия для Монголии - Власть. № 4. С. 130-134.

Грайворонский В.В. 1997. Современное аратство Монголии: социальные проблемы переходного периода (1980-1995 гг.). М.: Восточная литература. 184 с.

Грайворонский В.В. 2018. Монголия: пастбищно-кочевое животноводство рекордный рост скота и экологическая угроза. - Азия и Африка сегодня. № 9. С. 49-55.

Михалев А.В. 2012. «Золотая лихорадка» в Монголии и проблема трансформации кочевого общества. - Вестник Бурятского государственного университета. № 8. C. 196-203.

Babiker M. 2001. Resource Competition and Conflict: Herder/Farmer or Pastoralism/Agriculture? - African Pastoralism: Conflict, Institutions, and Government (ed. by M.A.M. Salih, T. Dietz, A.G.M. Ahmed). Pluto Press. P. 134-144. 
Barcus H.R. 2018. Contested Space, Contested Livelihoods: A Review of Mongolia's Pastureland Management and Land-Tenure Reform. - Geographical Review. Vol. 108. No. 1. P. 138-157.

Hannam I. 2017. International Pastoral Land Law. - International Farm Animal, Wildlife and Food Safety Law. Springer, Cham. P. 599-628.

Suzuki Y. 2013. Conflict between Mining Development and Nomadism in Mongolia. - The Mongolian Ecosystem Network. Tokyo: Springer. P. 269-294.

The Mongolian Ecosystem Network: environmental issues under climate and social changes (ed. by N. Yamamura, N. Fujita, A. Maekawa). 2012. Springer Science \& Business Media. $315 \mathrm{p}$.

Zhang M.A., Borjigin E., Zhang H. 2007. Mongolian Nomadic Culture and Ecological Culture: On the Ecological Reconstruction in the Agro-pastoral Mosaic Zone in Northern China. - Ecological Economics. Vol. 62. No. 1. P. 19-26.

GOMBOZHAPOV Aleksandr Dmitrievich, Cand.Sci. (Hist.), Leading Researcher at the Department of History and Culture, Institute for Mongolian, Buddhist and Tibetan Studies, Siberian Branch of Russian Academy of Sciences (6 Sakh yanovoj St, Ulan-Ude, Republic of Buryatia, Russia, 670047; agombozh@gmail.com)

\section{SOME NOTES ON THE NOMADISM OF MODERN MONGOLIA: THE ANTHROPOLOGY OF RESOURCE CONFLICT}

Abstract. The article is devoted to the analysis of the deep-seated changes occurring in the nomadism of Mongolia. The author notes that the traditional nomadic way of life has faced a number of challenges. In the conditions of rapid growth of the market economy, pastureland use has faced serious competition from mining enterprises and producers of agricultural crops. In addition to the conflict of interests between subjects with different economic activities, the internal struggle for pastures among the nomads themselves is growing.

Keywords: Mongolia, nomads, nomadic economy, resources, conflict 